\title{
Eksistensi Budaya Pappaseng Sebagai Sarana Pendidikan Moral
}

\author{
Dewi Handayani ${ }^{1}$, Sunarso ${ }^{2}$ \\ Pendidikan Pancasila dan Kewarganegaraan, Universitas Negeri Yogyakarta, Indonesia \\ 1'dewi15.handayani@gmail.com
}

Penelitian ini bertujuan menganalisis pentingnya eksistensi budaya pappaseng sebagai saran pendidikan moral bagi para generasi muda agar memiliki sikap dan perilaku yang berkarakter dan bijaksana ditengah arus globalisasi. Pappaseng adalah karya sastra tradisional yang merupakan karya seni yang menggunakan bahasa sebagai media dalam pemaparan, diwariskan secara turun temurun sebagai wasiat dalam suku Bugis. Metode dalam penelitian ini menggunakan pendekatan kualitatif dengan desain etnografi. Subjek penelitian sebanyak enam belas orang mahasiswa asrama putri Sulawesi Selatan yang ada di Yogyakarta. Teknik pengumpulan data melalui wawancara yang mendalam dan studi kepustakaan. Hasil penelitian menujukan bahwa perkembangan zaman membuat nilai-nilai Pappaseng sedikit demi sedikit mulai terkikis dalam diri beberapa individu, namun masih banyak masyarakat yang tetap mempertahankan budaya Pappaseng karena merupakan pedoman hidup yang diwariskan dari leluhur dan nilai yang terkandung dalam budaya Pappaseng relevan dengan nilainilai agama Islam. Pentingnya pendidikan berbasis budaya karena dapat meningkatkan kualitas hidup manusia seperti Pappaseng yang dapat digunakan sebagai sarana pendidikan moral dan pembentukan karakter bagi manusia.

Kata kunci : Budaya, Pappaseng, Pendidikan Moral

\section{The Existence of Pappaseng Culture as a Means of Moral Education}

This study aims to analyze the importance of the existence of Pappaseng culture as a moral education suggestion for young people so that they have character and wise attitudes and behaviors in the midst of globalization. Pappaseng is a traditional literary work which is a work of art that uses language as a medium in presentation, passed down from generation to generation as a will in the Bugis tribe. The method in this research uses a qualitative approach with ethnographic design. Research subjects were sixteen South Sulawesi female student dormitories in Yogyakarta. Data collection techniques through in-depth interviews and literature study. The research results show that the development of the times has made Pappaseng's values gradually eroded in some individuals, but there are still many people who still maintain Pappaseng culture because it is a life guide inherited from ancestors and the values contained in Pappaseng culture are relevant to the values Islam. The importance of culture-based education because it can improve the quality of human life such as Pappaseng which can be used as a means of moral education and character building for humans.

Keywords : Culture, Pappaseng, Moral Education

Proses Review : 1 - 20 Mei 2020, Dinyatakan Lolos: 29 Mei 2020 


\section{PENDAHULUAN}

Pengaruh kecanggihan tekhnologi informasi dan komunikasi memang tidak bisa dipungkiri, kita tidak bisa menolak dan menghindari arus globalisasi dan modernisasi kebudayaan yang berjalan begitu cepat karena merupakan konsekuensi dari dunia yang mengglobal. Globalisasi merupakan kekuatan dominan yang membentuk kedalam lingkungan peradaban dan budaya yang bernilai positif dan negatif (Handayani, 2008: 156).

Kehadiran globalisasi membawa manfaat positif bagi negara-negara maju sedangkan globalisasi membawa kemudharatan bagi negara yang berkembang dan negara yang terbelakang (Wiyono, 2010: 10). Hal tersebut seperti yang diungkapkan oleh Mubah (2011: 302-303) negara-negara maju merupakan pemimpin utama dalam proses globalisasi karena negara-negara maju tersebut merupakan penguasa teknologi, informasi dan komunikasi, sedangkan negara-negara berkembang merupakan penonton bagi adanya proses globalisasi. Masuknya budaya barat ke Indonesia menyebabkan budaya lokal Indonesia semakin kurang dinikmati dan ditinggalkan karena masyarakat sedang menyukai budaya barat yang tengah hadir akibat proses globalisasi.

Globalisasi hadir di Indonesia membawa dampak baik dan buruk. Globalisasi membuat hilangnya budaya lokal asli Indonesia, memudarnya rasa patriotisme dan rasa nasionalisme, adanya pengikisan nilai-nilai budaya lokal, dan munculnya gaya hidup yang kearah barat-baratan (Suneki, 2012: 3017). Sedangkan menurut Setyaningrum (2018: 107-109) kemajuan teknologi menyebabkan kearifan budaya lokal semakin hari kian luntur, seperti hilangnya nilai budaya kesenian yang terjadi karena dialih fungsikan sarananya. Indonesia memiliki banyak sekali kearifan budaya lokal namun kearifan budaya lokal tersebut mengalami pergeseran dan ditinggalkan akibat perubahan zaman. Menurut Yulinis (2019: 276) globalisasi mengakibatkan timbulnya dampak baik yang mengakibatkan kemajuan dan dampak buruk yang mengakibatkan kemunduran. Dampak buruk adanya globalisasi membuat kemunduruan yang tajam bagi budaya karena adanya kompetisi dalam persaingan antar budaya.

Arus modernisasi membawa banyak perubahan pada kehidupan masyarakat. Salah satu dampak buruk yang terjadi adanya perubahan yang mengarah pada krisis moral dan akhlak. Hampir semua elemen bangsa merasakan penyakit krisis moral yang tengah menjalar bangsa ini. Masih ada anak-anak zaman sekarang yang menggunakan ungkapan kasar dalam berbicara yang menyimpang dari nilai-nilai kearifan lokal dan luhur (Noor, 2011: 42-43). Era globalisasi saat ini membuat para generasi muda dihadapkan pada pilihan nilai-nilai yang dianggap baik. Adanya pengikisan nilai yang terjadi secara terbuka menyebabkan nilai-nilai yang dianggap baik oleh kelompok masyarakat belum tentu dianggap relevan dengan budaya masyarakat (Sanjaya, 2007: 273-274).

Peristiwa modernisasi menyebabkan pergeseran terhadap budaya yang menjadi identitas suatu bangsa. Seperti pergeseran pola berpakaian, pola berpikir, tingkah laku dan lain sebagainya yang mempengaruhi eksistensi kearifan budaya lokal (Jahid, 2011: 5). Sedangkan menurut Suparno (2018: 45) kebudayaan lokal Indonesia hampir menunjukan gejala punah karena peran para generasi muda semakin lemah dalam melestarikan budaya lokal Indonesia.

Selain karena adanya dampak globalisasi yang membuat beberapa nilai-nilai budaya lokal menjadi luntur, ada juga kasus etnosentrisme yang bisa menimbulkan konflik antar kelompok masyarakat tertentu yang berakibat pada lunturnya budaya tertentu. Kasus etnosentrisme merupakan kasus yang sering kali terjadi. Diawali dengan adanya penghakiman terhadap kebudayaan suatu kelompok masyarakat tertentu yang dilakukan oleh kelompok masyarakat lain dengan cara membanding-bandingkan dan menganggap bahwa kebudayaannya lebih baik (Giddens, 1990: 39). Adanya penilain budaya sendiri yang dianggap lebih baik dari pada budaya lain dapat menimbulkan permasalahan juga (Suryandari, 2017: 25).

Tidak ada yang menyangkal bahwa aspek penting dalam menghadapi kehidupan manusia adalah karakter. Untuk bisa menghadapi kehidupan dimasa depan manusia harus memiliki karakter yang kuat. Karakter yang kuat akan menjadikan manusia yang tahan banting, bermental baja, pantang menyerah dan mampu menghadapi berbagai bahaya yang datang. Kehidupan manusia yang semakin maju dalam era hiperkompetitif menuntut manusia untuk memiliki karakter yang kuat agar mampu menjadi pemenang dalam setiap keadaan (Ma'mur, 2012, 23).

Dewasa ini, perkembangan dekadensi moral para generasi muda semakin memilukan. Karakter yang seharusnya dipertaruhkan ditempat yang seyogyanya justru sebaliknya karakter justru dipertaruhkan ditempat yang tidak seyogyanya. Jika krisis moral dan karakter ini dibiarkan begitu saja maka bangsa ini menuju pada the lost generation. Hal ini memicu diskusi dari masyarakat sehingga ada kubu yang pro dan ada yang kontra, adanya hal tersebut merupakan sesuatu yang wajar karena nalar masyarakat berbeda-beda ini menandakan bahwa adanya kemauan dari masyarakat untuk berpikir memikirkan bangsa ini (Barnawai et al, 2012). Kehidupan sosial masyarakat yang terus berjalan menunjukan sifat yang statis mekanistis. Hal ini membuat munculnya berbagai macam keadaan masyarakat yang menunjukan gejala frustasi, depresi, cepat marah, tindakan yang anarki, dan berbagai keadaan sosial lainnya (Widodo, 2016: 6).

Tampaknya masyarakat Indonesia belum dapat berlapang 
dada karena faktanya pendidikan di Indonesia dihadapkan pada masalah pokok sistem pendidikan nasional. Seperti masalah moral dan akhlak peserta didik, manajemen pendidikan yang tidak sejalan dengan pembangunan nasional dan kurangnya sumber daya tenaga pendidik yang profesionalisme. Pelaksanaan pembangunan nasional dalam berbagai bidang mengalami peningkatan yang begitu baik. Namun siapa sangka bahwa peningkatan tersebut juga membawa dampak negatif bagi kehidupan bangsa karena banyak nilai moral dan karakter yang memudar. Seperti nilai budaya, nilai solidaritas, kekeluargaan, kejujuran, rasa malu, bahasa, dan nasionalisme (Masita, 2012: 305). Akhir-akhir ini permasalahan pendidikan di Indonesia juga dihadapkan pada mundurnya moral generasi muda seperti terjadinya tawuran antar pelajar, narkoba, sikap tidak sopan kepada guru, beredarnya foto dan video porno dikalangan pelajar dan lain sebagainya.

Setiap anak yang lahir kedunia memang memiliki tabiat yang berbeda-beda. Seperti adanya perbedaan temperamen, bakat dan kebutuhan masing-masing. Perbedaan tersebut tidaklah salah karena sejatinya perbedaan itu indah dan bisa dijadikan potensi untuk mengembakan karakter yang baik sehingga kelak ketika dewasa akan memberikan kontribusi baik bagi masyarakat (Priyatna, 2011). Maraknya kasus-kasus moral dan karakter yang terjadi menarik perhatian pemerintah. Pemerintah sampai melibatkan 16 kementerian untuk memberikan saran, masukan, dan gambran tentang pendidikan karakter dan budaya bangsa ini. Hal ini menandakan bahwa begitu besarnya perhatian pemerintah terhadap pengembangan budaya dan karakter bangsa negeri ini (Sulhan, 2011).

Kearifan lokal merupakan bagian dari kontruksi budaya. Kearifan lokal yang tumbuh dan berkembang dalam masyarakat merupakan pengetahuan yang menghasilkan nilai-nilai adat yang luhur dan dijadikan pedoman hidup oleh masyarakat. Kearifan budaya lokal dapat dijadikan sebagai salah satu sarana pendidikan untuk membentuk karakter dan moral. Menurut Nuraini \& Agus (2016: 46). Budaya lokal merupakan segala sesuatu yang bernilai yang mengandung aktifitas-aktifitas dan simbol-simbol terentu dalam lapisan masyarakat yang dijadikan pedoman hidup bagi masyarakat tertentu. Budaya lokal merupakan terobasan baru yang bisa digunakan untuk meningkatkan mutu pendidikan. Sedangkan menurut Diana (2012: 194) pendidikan berbasis budaya lokal merupakan usaha untuk memperkuat kemajemukan didalam kehidupan bangsa dengan memberikan pengetahuan yang dapat melahirkan jiwa-jiwa yang kuat.

Indonesia merupakan salah satu negara yang memiliki keanekaragaman adat istiadat, bahasa, dan budaya. Kebudayaan berasal dari kata sanksekerta yaitu "buddhayah" yang merupakan bentuk jamak dari buddhi yang memiliki makna "budi" atau "akal". Hal tersebut membuat ke- budayaan diartikan sebagai segala sesuatu yang berkaitan dengan akal (Koentjaraningrat, 2015: 146). Kebudayaan bersifat dinamis artinya kebudayaan akan mengalami perubahan dari masa ke masa. Perubahan terjadi karena adanya faktor eksternal dan internal yang mempengaruhi kehidupan manusia. Nilai-nilai budaya yang terkandung dalam setiap kebudayaan yang ada di Indonesia mempengaruhi karakter bangsa Indonesia. salah satu kearifan kebudayaan lokal yang memiliki nilai dan sarat dengan karakter yang tumbuh dalam masyarakat bugis adalah “pappaseng" (Nurhaeda, 2013: 296-297).

Pappaseng adalah satu bentuk sastra klasik tradisional yang merupkan salah satu karya seni suku Bugis yang menggunakan bahasa sebagai media pemaparan (Iskandar, 2016: 1). Pappaseng merupakan satu bentuk sastra klasik suku Bugis yang awalnya dituturkan akan tetapi setelas mengenal tulisan pappaseng kemudian ditulis dalam lontar Seiring perkembangannya pappaseng dibukukan. Pappaseng kemudian dijadikan pegangan hidup oleh masyarakat Bugis karena nilai-nilai luhur yang terkandung didalam pappaseng. Selain itu pappaseng juga dijadikan pedoman untuk menghadapi berbagai macam masalah kehidupan duniawi dan akhirat (Jemmain, 2011: 357-358). Sedangkan menurut Rahmi et al (2017: 229) pappaseng merupakan kearifan kebudayaan lokal yang perlu untuk dihidupkan kembali karena nilai-nilai yang terkandung didalamnya merupakan nilai yang khas dengan bangsa Indonesia dan nilai-nilai budaya pappaseng merupakan nilai yang mampu diresapi.

Dari beberapa hal yang telah dipaparkan diatas, membuat peneliti merasa tertarik dan perlu memberikan pemahaman pentingnya budaya lokal di Indonesia dalam bentuk partisipasi sebagai generasi muda berupa sumbangsih dalam bentuk gagasan tertulis yang berjudul "eksistensi budaya Pappaseng sebagai sarana pendidikan moral."

\section{METODE PENELITIAN}

Metode yang digunakan dalam penelitian ini adalah pendekatan kualitatif dengan desain etnografi. Penelitian kualitatif sendiri menurut Sugiyono (2017: 9) merupakan penelitian yang hasil akhirnya tidak menitikberatkan pada abstraksi melainkan pada arti, peneliti harus pandai dalam menggali informasi kepada informan penelitian karena peran dan kemampuan peneliti sangat mempengaruhi tingkat kesuksesan penelitian yang bersifat alami, setelah memperoleh data dari informan maka peneliti harus mengolah data melalui proses triangulasi. Sedangkan metode etnografi merupakan penelitian yang berusah menggambarkan, menganalisa dan menafsirkan bagian-bagian dari kelompok budaya seperti pola perilaku, kepercayaan dan bahasa yang berkembang dalam suatu kelompok dari masa ke masa. Penelitian etnografi lebih banyak menggunakan fase wawancara. Metode etnografi adalah bagian dari 
prosedur penelitian kualitatif (Creswell, 20012: 462).

Penelitian ini dilaksanakan pada bulan November sampai Desember 2019. Lokasi penelitian dilakukan di Asrama Mahasiswa Putri Provinsi Sulawesi Selatan yang ada di Jalan Johar Nurhadi No.9, Kotabaru, Kec. Gondokusuman, Kota Yogyakarta, Daerah Istimewa Yogyakarta 55224. Subjek penelitian sebanyak enam belas orang informan, pemilihan informan dengan menggunakan teknik purposive. Teknik pengumpulan data melalui wawancara yang mendalam dan studi kepustakaan. Dalam penelitian ini, peneliti menggunakan wawancara semiterstruktur. Keabsahan data menggunakan triangulasi sumber. Hasil pengumpulan data yang diperoleh dari lapangan kemudian dianalisis dengan menggunakan teknik analisis data yang dipaparkan oleh Miles dan Haberman meliputi tahap reduksi, penyajian, kesimpulan dan verifikasi data.

\section{ANALISIS DAN INTEPRETASI DATA}

Penelitian ini bertujuan untuk menganalisis pentingnya eksistensi budaya Pappaseng sebagai saran pendidikan moral bagi pada generasi muda agar memiliki sikap dan perilaku yang berkarakter dan bijaksana ditengah arus teknologi yang semakin canggih akibat globalisasi bagi para generasi muda karena pendidikan berbasis budaya memiliki dampak positif bagi kehidupan manusia. Seperti budaya Pappaseng yang dapat dijadikan sebagai sarana yang bermanfaat bagi manusia. Pappaseng dapat dijadikan sebagai sarana pendidikan, pedoman kehidupan, media kontrol sosial, dan pelindung norma yang hidup didalam masyarakat (Iskandar, 2016: 18).

\section{Eksistensi dan Upaya Melestarikan Kearifan Budaya Lokal Pappaseng dalam Era Modernisasi}

Etnis Bugis merupakan salah satu etnis terbesar yang ada di Indonesia. Etnis Bugis merupakan bagian dari etnis Makassar yang berada di Sulawesi Selatan. Etnis Bugis memiliki beragam kearifan budaya lokal yang dijadikan pandangan hidup. Pada hakekatnya kebudayaan dan pandangan hidup orang Bugis sama dengan kebudayaan dan pandangan hidup orang Makassar. Oleh karena itu membahas tentang budaya Bugis sulit dilepaskan dengan pembahasan tentang budaya Makassar. Kota Makassar merupakan kota terbesar keempat di Indonesia dan terbesar di Kawasan Timur Indonesia memiliki luas areal 175,79 km2 dengan penduduk 1.112.688, sehingga kota ini sudah menjadi kota Metropolitan. Sebagai pusat pelayanan di KTI, Kota Makassar berperan sebagai pusat perdagangan dan jasa, pusat kegiatan industri, pusat kegiatan pemerintahan, simpul jasa angkutan barang dan penumpang baik darat, laut maupun udara dan pusat pelayanan pendidikan dan kesehatan. Sebagai salah satu etnis terbesar Bugis memiliki banyak sekali kebudayaan dan kearifan lokal yang dapat dijadikan sebagai sarana pendidikan karena nilainilai yang terkandung dalam kearifan budaya lokal dapat membentuk perilaku manusia. Hal ini senada dengan yang diungkapkan oleh Zamzami \& Hendrawati (2014: 40) kearifan budaya lokal merupakan local wisdom yang diturunkan dari nenek moyang yang tumbuh dan berkembang didalam masyarakat sebagai akibat adanya keinginan untuk hidup lebih baik dengan aturan hidup. Nilai-nilai kearifan budaya lokal mampu membentuk kepribadian setiap individu sehingga nilai-nilai kearifan budaya lokal tersebut diajarkan dan diwariskan kepada generasi ke generasi berikutnya agar setiap generasi mempunyai kepribadian yang baik dan mampu menjalani kehidupan dengan baik. Salah satu kearifan budaya lokal Bugis yang memiliki nilai-nilai luhur yang mampu dijadikan sebagai sumber pendidikan adalah Pappaseng.

Pappaseng salah satu jenis naskah lama yang disebut lontaraq pappaseng merupakan wasiat berharga yang berisi nasihat bermakna bagi para generasi muda karena didalamnya berisi ajakan moral yang harus dipatuhi. Pappaseng sebagai falsafah hidup masyarakat Bugis yang bertujuan untuk membentuk karakter yang baik. Nilai utama yang terkandung didalamnya merupakan nilai pendidikan yang sangat diperlukan untuk membina generasi muda (Jumrana, 2018: 1-2). Sedangkan menurut Mallombasi (2014: 14) Pappaseng adalah suatu petuah dari masa lalu dari Sulawesi Selatan yang berhubungan dengan kelangsungan hidup didalamnya memuat pandang hidup dan tata cara berpikir. Pappaseng masih dipegang teguh sebagai pedoman hidup bagi masyarakat yang mempercayainyai karena didalamnya mengandung nilai budaya dan pesan etika (Sewang \& Asdy, 2010). Sedangkan menurut Pelras (2006: 248) Pappaseng adalah kumpulan pesan atau petunjuk hidup yang diwariskan nenek moyang masyarakat Bugis sebagai warisan kearifan budaya lokal. Hal tersebut diperkuat dengan hasil wawancara yang menunjukan bahwa:

"Pappaseng merupakan falsafah hidup masyarakat Bugis yang diwariskan dari nenek moyang. Banyak sekali nilai-nilai luhur yang terkandung didalamnya yang bisa dijadikan pedoman hidup bagi generasi muda. Nilai edukatif dari Pappaseng sangat berguna bagi generasi muda dalam menjalankan kehidupan apalagi diera globalisasi seperti saat ini(NF, ZT, \& ZB)"

Keberadaan Pappaseng sangat dimuliakan kehadirannya dalam masyarakat Bugis karena seseorang yang memegang teguh Pappaseng dalam hatinya maka perilaku dan pandangannya akan senantiasa baik dan terjaga. Namun sebaliknya jika seseorang kehilangan Pappaseng didalam hatinya maka seseorang tersebut akan mengalami kesulitan. Seperti kesulitan berinteraksi, dan lain sebagainya. Nilai yang terkandung dalam Pappaseng merupakan nilai yang relevan dengan nilai ajaran Islam (Abbas, 2013: 282). Sedangkan menurut Agustang (2018: 17) mengungkapkan bahwa pesan-pesan yang ada didalam Pappaseng merupakan pesan yang relevan dengan ajaran agama Islam yang diajarkan oleh Nabi Muhammad SAW, untuk itu budaya Pappaseng harus dilestarikan dan diajarkan secara turun 
temurun. Hal tersebut diperkuat dengan hasil wawancara yang menunjukan bahwa:

"Bagi saya memiliki Pappaseng sebagai falsafah hidup memberikan dampak yang positif bagi diri saya dalam menjalankan kehidupan karena nilai Pappaseng tidak bertentangan dengan ajaran agama saya yaitu Islam. Jika seseorang kehilangan Pappaseng dalam hatinya maka saya yakin pasti seseorang tersebut akan merasa ada sesuatu yang hilang dari hidupnya. Seseorang tersebut akan mengalami kesulitan dalam menjalani hidupnya (FSK \& AS)."

Perkembangan zaman yang semakin canggih membawa dampak positif dan negatif bagi perkembangan kebudayaan lokal. Salah satu dampak negatif tersebut dirasakan bagi eksistensi budaya Pappaseng. Seperti yang diungkapkan oleh Jumana (2018: 8) perkembangan zaman yang bersifat dinamis menyebabkan pergeseran nilai-nilai yang terdapat dalam budaya Pappaseng. Sedangkan menurut Fathiyah et al. (2018: 122) seiring perkembangan zaman nilai-nilai luhur budaya Pappaseng tidak diajarkan dan tidak dijadikan pedoman hidup oleh beberapa orang. Hal tersebut diperkuat dengan hasil wawancara yang menunjukan bahwa:

"Seiring perkembangan zaman budaya Pappaseng masih dipertahankan karena merupakan falsafah hidup yang sudah mendarah daging. Walaupun ada beberapa orang yang mungkin mulai berkurang budaya Pappasengnya karena tidak mampu menahan pengaruh perkembangan zaman. Namun masih banyak sekali yang tetap mempertahankan budaya Pappaseng sebagai pedoman hidup (SIW \& ZB )."

Hasil penelitian Rasak et al. (2019: 95) menunjukan bahwa Pappaseng sebagai pedoman hidup masih dipertahankan oleh para mahasiswa karena pengaruh positif yang ditemukan dalam budaya Pappaseng itu sendiri membawa perekat bagi hubungan individu yang dijadikan pandangan hidup.

Pengaruh globalisasi dapat diimbangi dengan adanya budaya lokal. Karena budaya lokal merupakan sumber budaya yang dijadikan pedoman bagi generasi muda (Rosidi, 2010: 72-73). Salah satu manfaat kearifan budaya lokal Pappaseng adalah dapat menanggulangi pengaruh-pengaruh buruk budaya luar yang dapat merusak moral bangsa karena Pappaseng merupakan penerang bagi manusia agar bisa menemukan hakikat hidup yang baik (Mustafa, 2013: 204).

Keberadaan Pappaseng sebagai salah satu kearifan budaya lokal yang memiliki nilai-nilai luhur haruslah dilestarikan secara turun-temurun dengan berbagai cara yang mengarah positif. Menurut Fathiyah (2018: 127) Pappaseng dapat diwariskan kepada generasi penerus melalui berbagai macam bentuk proses. Seperti adanya proses enkulturasi dan sosialisasi kepada generasi selanjutnya. Sedangkan menurut Abbas (2013: 272) pelestarian budaya Pappaseng dapat dilakukan melalui pendidikan non formal dan pendidikan formal. Pendidikan non formal dapat diajarkan dilingkungan keluarga dan lingkungan sekitar seseorang hidup. Sedangkan pendidikan formal dapat diajarkan melalui lembaga resmi seperti sekolah dengan memasukannya kedalam pembelajaran mata pelajaran IPS.

Pesan-pesan yang terdapat didalam Pappaseng dapat dilestarikan dengan disosialisasikan kembali kepada para generasi penerus dengan harapan para individu meresapi dan mengaplikasikannya dalam kehidupan sehari-hari. Kemudian setiap orang tua dapat mengajarkan anak-anaknya dengan mewariskan nilai-nilai keraifan lokal tersebut melalui pemberian pendidikan karakter sejak dini kepada anak-anaknya (Iswary, 2012: 103). Hal tersebut diperkuat dengan hasil wawancara yang menunjukan bahwa:

"Sebagai pedoman hidup tentu Pappaseng harus dilestarikan yang dimulai dari kesadaran sendiri bahwa Pappaseng memiliki nilai yang penting. kemudian adanya proses sosialisasi dari lintas generasi ke generasi selanjutnya. Sehingga dengan harapan budaya Pappaseng ini akan terus eksis sebagai pedoman hidup yang akan membawa dampak baik bagi setiap individu (LS, AF, AB, \& NG)."

Isi dalam Pappaseng merupakan pesan-pesan yang berbentuk manuskrip yang mengajarkan tentang pemberian tuntunan hidup kepada masyarakat agar menjadi manusia berkarakter baik dalam semua dimensi. Seperti dimensi rasa, raga, pikiran, hati, dan karsa, baik ketika menjadi seorang yang memiliki jabatan maupun menjadi anggota masyarakat biasa (Iswary, 2012: 98-99).

Budaya atau adat istiadat yang ada didalam masyarakat tertentu merupakan inspirasi sumber hukum bagi masyarakat tersebut. Sehingga kehadiran budaya atau adat istiadat harus terus dipertahankan dan dilestarikan karena nilai budaya nilai-nilai budaya membawa dampak positif dan membantu perkembangan bagi kehidupan manusia agar lebih baik dan memiliki harga diri (Said, 2014: 156). Sedangkan menurut Sanusi (2015: 208) nilai kearifan budaya lokal harus diaplikasikan dalam kehidupan sehari-hari bukan hanya dimengerti dan dipahami dalam pikiran. Perlu adanya tindakan untuk merefleksikan nilai kearifan budaya lokal tersebut agar mendapatkan manfaat dari nilai kearifan budaya lokal.

\section{Kearifan Budaya Lokal Pappaseng sebagai sarana Pendidikan Moral}

Urgensi pendidikan yang berakar pada budaya dicontohkan oleh negara Jepang. Jepang mampu membuat rakyatnya sejahterah dan makmur di kawasan Asia Pasifik. Keberhasilan jepang dalam mengembangkan pendidikan berbasis budaya tradisional menjadi senjata yang mujarab dalam memajukan negara di tengah budaya barat (Setyono, 2008: 44). Urgensi pengkajian budaya lokal seba- 
gi sumber budaya bagi anak didik akan menjadi senjata yang dapat mengimbangi adanya gencatan budaya global (Rosidi, 2010: 72-73). Identitas budaya pada anak terbentuk melalui sebuah pendidikan yang ada dalam etnisitas tertentu. Menurut Liliweri (2005: 43) identitas budaya meliputi pembelajaran dan adanya penerimaan terhadap tradisi, bahasa, keturunan, sifat bawaan, agama dan suatu kebudayaan yang ditampilkan oleh anggota dari suatu kelompok etnik tertentu.

Konsep pendidikan berbasis budaya dapat ditemukan dalam adat istiadat, kearifan lokal dan kebudayaan yang ada di Indonesia. menurut Daryanto (2012: 136) kebudayaan berpengaruh dalam meningkatkan kualitas hidup manusia. Kebudayaan diperoleh manusia karena adanya hubungan interaksi terhadap lingkungan. Pendidikan tidak bisa dipisahkan dari ruang lingkup kebudayaan. Hal tersebut diperkuat dengan hasil wawancara yang menunjukan bahwa:

"Pendidikan berbasis budaya itu penting karena kearifan budaya lokal yang ada tumbuh dan berkembang dalam masyarakat itu mengandung nilai-nilai luhur yang mampu dijadikan sebagai pedoman dalam menghadapi tantangan kehidupan (DAP \& EG)."

Nilai-nilai luhur dapat diperoleh dari pendidikan moral yang dapat ditemukan dari kearifan budaya lokal di berbagai wilayah Indonesia. Indonesia merupakan negara yang kaya akan corak budaya. Pendidikan moral sangat mungkin untuk didiberikan di Inonesia karena dapat melahirkan generasi muda yang memiliki moralitas tinggi sehingga dapat meningkatkan harga diri yang menyangkut harkat dan martabat diri di era globalisasi. Untuk itu perlu adanya pembekalan nilai-nilai yang dikemas dalam pendidikan berbasis kearifan budaya lokal. Pendidikan berbasis kearifan budaya akan menjadi senjata yang mampu menjaring berbagai informasi agar tidak memasuki tempat yang salah sehingga hal ini akan membuat Indonesia menjadi negara yang bermoral tinggi (Widodo et al, 2017: 339-347). Generasi muda yang berbudaya dihasilkan dari adanya pendidikan budaya (pendidikan berbasis kearifan lokal (Sujipto, 2013: 472).

Salah satu kebudayaan Indonesia yang dapat digali sebagai saran pendidikan moral bangsa adalah Pappaseng. Pappaseng berbentuk lontara yang pada mulanya disampaikan secara lisan dan hingga akhirnya dikumpulkan dalam bentuk lontra (Elfira, 2013: 22). Sedangkan menurut (Tamsil, 2019: 9) Pappaseng mengajarkan manusia untuk memiliki pengetahuan yang luas sehingga dengan pengetahuan tersebut akan membantu manusia untuk bertingkah dengan bijak. Budaya Pappaseng mengandung beberapa nilai diantaranya nilai pendidikan, nilai moral, nilai filosofis, nilai budaya, dan nilai agama.

Pappaseng berisi nasihat dan petunjuk hidup yang diwariskan oleh nenek moyang kepada anak cucunya untuk dijadikan pedoman hidup agar dapat menjalani kehidupan yang baik (Punagi et al, 1983: 3). Sedangkan menurutu Fathiyah (2018: 120) Pappaseng sebagai salah satu kearifan budaya lokal yang memiliki beberapa nilai pembentukan karakter diantaranya disiplin, menjaga kehormatan, taat suami, pandai memasak, dermawan, dan disiplin.

Menurut (Suhra, 2018: 222) Pappaseng memiliki nilai karakter apabila diajarkan dan diaplikasin dalam kehidupan sehari-hari maka orang tersebut akan merasakan manfaatnya. seperti adanya nilai kepedulian, toleransi, demokrasi, jujur, dan sabar. Sedangkan menurut Rahmi et al. (2017: 236-237) Pappaseng mengandung empat nilai diantaranya nilai kejujuran, nilai keteguhan, nilai keberanian dan nilai kecakapan. Hal tersebut diperkuat dengan hasil wawancara yang menunjukan bahwa:

"Nilai-nilai yang terkandung dalam budaya Pappaseng sangat beragam seperti adanya nilai jujur, nilai tanggungjawab, nilai sabar, nilai toleransi, nilai demokrasi dan lain sebagainya. Nilai-nilai inilah yang akan membentuk moral dan karakter individu apabila diajarkan dengan tepat (NA, \& NG)."

Nilai memang berhubungan dengan manusia. Agar tetap dianggap ada dalam masyarakat maka harus menjunjung tinggi nilai-nilai yang dipercaya dalam masyarakat tertentu. Sebaliknya jika tidak mampu menjunjung tinggi nilai yang dipercaya dalam masyarakat maka eksistensinya akan menghilang. Hal ini senada dengan pendapat Setiadi (2012: 116) Nilai sangat berkaitan erat dengan kehidupan manusia. Baik nilai etika, estetika hingga nilai yang berkaitan dengan keyakinan hidup. Nilai merupakan peraturan yang menentukan bobot tinggi atau rendahnya suatu perbuatan atau benda. Peraturan ini dapat berupa penerimaan atau penolakan (Semi, 2013: 54-55).

Karya sastra mengandung banyak sekali pesan tentang moral yang dapat menanamkan dan menumbuhkan nilainilai kepribadian yang luhur bagi setiap individu (Mansyur, 2016: 1). Seperti salah satu karya sastra yang telah menjadi pedoman hidup bagi masyarakat bugis yaitu Pappaseng. Pappaseng sebagai salah satu budaya yang hidup dalam masyarakat Mandar yang mengajarkan manusia untuk menjadi manusia yang baik dan mempraktikan halhal yang baik kedalam kehidupan sehari-hari. Pappaseng merupakan salah satu sarana yang dijadikan dalam pengajaran pendidikan moral bagi manusia (Tamsil, 2019: 6). Hal tersebut diperkuat dengan hasil wawancara yang menunjukan bahwa:

"Pappaseng sebagai pedoman hidup masyarakat Bugis selain sebagai saran pembentukan karakter juga sebagai sarana pendidikan moral didalamnya bagi masyarakat Bugis (NF)."

Pappaseng dapat dikatakan bersinonim dengan pangaja yang memiliki makna nasihat, namun Pappaseng tidak cukup dimaknai sama dengan banyak kata pangaja. Pap- 
paseng lebih menekankan pada ajaran moral yang patut dituruti, sedangkan pangaja menekankan pada suatu tindakan yang harus dilakukan atau dihindarkan (Depdiknas, 2010: 215). Sedangkan Rahmi et al (2017: 228) Pappaseng hadir dalam hidup manusia memiliki tujuan hidup bagi manusia untuk membangun kualitas individu untuk menjadi pribadi baik yang ideal sehingga mampu membawa berkah dan perubahan bagi alam. Pappaseng datang dalam kehidupan masyarakat Bugis sebagai sarana media pendidikan moral.

Menurut Rahmi (2016: 123) kehadiran Pappaseng sebagai media pendidikan moral bagi manusia tentu membawa harapan agar manusia menjadi makhluk yang beradab. Sedangkan Nurhaeda (2018: 311) Pappaseng sebagai pendidikan moral yang dijadikan pegangan hidup harus berhati-hati dalam memutuskan segala sesuatu tentang hidup karena akan berimbas pada tujuan hidup yang akan diambilnya.

Keberadaan Pappaseng dalam masyarakat Bugis sangat dijunjung tinggi karena Pappaseng menekankan pada ajaran etika dan moral. Seperti etika berinteraksi dan berhubungan dengan masyarakat sekitar dan orang tua (Abbas, 2013: 282). Moral pribadi seperti jujur, adil dan bertanggungjawab akan berpengaruh terhadap moral publik karena moral publik akan melahirkan etika yang baik bagi kehidupan sosial seseorang (Kurniawan, 2018: 80). Didalam kehidupan masyarakat religius tradisional moral hadir karena diwariskan secara indoktrinasi kepada para generasi ke generasi (Rukiyati, 2017: 73).

\section{SIMPULAN}

Berdasarkan uraian diatas dapat disimpulkan bahwa Pappaseng merupakan salah satu kearifan budaya lokal yang tumbuh dan berkembang pada masyarakat Bugis dan merupakan warisan budaya leluhur. Falsafah Pappaseng awalnya merupakan salah satu karya seni yang menggunakan bahasa sebagai media pemaparannya secara turun temurun dari generasi kegenarasi yang merupakan wasiat sehigga begitu melekat dan mendarah daging dalam kehidupan masyarakat Bugis karena jika seseorang kehilangan Pappaseng dalam dirinya maka seseorang akan merasa ada yang hilang dalam dirinya dan akan mengalami kesulitan dalam menjalani hidup. Keberadaan Pappaseng mengandung nilai-nilai yang yang relevan dengan agama dan pancasila. Untuk itu Pappaseng harus dilestarikan dengan cara yang dimulai dengan kesadaran dalam diri setiap indivi$\mathrm{du}$, mensosialisasi budaya Pappaseng kepada generasi ke generasi selanjutnya dan melalui lembaga formal dengan mengintegrasikannya dalam pembelajaran IPS. Budaya Pappaseng harus dimiliki setiap individu tidak hanya untuk masyarakat Bugis namun untuk semua bangsa Indonesia.
Pendidikan berbasis budaya merupakan proses pembelajaran yang berusaha mengintegrasikan budaya dalam proses pembelajarannya karena budaya yang tumbuh dan berkembang didalam kehidupan masyarakat tertentu memiliki nilai-nilai luhur yang dapat dijadikan sebagai sarana pendidikan moral dan pembentukan karakter bagi generasi muda ditengah arus globalisasi. Bukan hanya moral pribadi jujur, bertanggungjawab, adil dan lain sebagainya yang penting namun moral publik juga penting karena dapat membantu manusia agar mampu beretika sopan santun dalam menjalani kehidupan.

\section{UCAPAN TERIMAKASIH / PENGHARGAAN}

Peneliti ingin mengucapkan terima kasih kepada Bapak Dr. Sunarso, M. Si yang telah membimbing dan mengarahkan penulis dalam menyusun artikel ini dari awal sampai akhir hingga terbit serta teman-teman mahasiswa Putri Sulawesi Selatan yang telah memberikan bantuan dan kerjasamanya sehingga penelitian ini dapat terlaksana dengan baik.

\section{DAFTAR RUJUKAN}

Abbas, I. (2018). Pappaseng: Kearifan Lokal Manusia Bugis Yang Terlupakan. Sosiohumaniora, 15(3), pp 272 - 284. Retrieved from http://jurnal.unpad.ac.id/sosiohumaniora/article/viewFile/5752/3064

Agustang, K. (2018). Korelasi Petuah Bugis Pappaseng Dengan Hadis-Hadis Tarbawi (Telaah Catatan Mappiase Gule Dalam 100 Ada-Ada Pappaseng Toriyolo). Jurnal Islamika: Jurnal Ilmu-Ilmu Keislaman, 18(1), pp 1-18. Retrieved from https://ejournal.iainkerinci.ac.id/index.php/ islamika/article/view/269/215

Barnawi et al. (2012). Strategi \& Kebijakan Pembelajaran Pendidikan Karakter. Yogyakarta: Ar-Ruzz Media.

Depdiknas. (2010). Nilai Budaya dalam Pappaseng Tomato: "Petuah Leluhur" Bunga Rampai Hasil Penelitian Bahasa dan Sastra. Balai Bahasa Ujung Pandang, Pusat Bahasa. Departemen Pendidikan Nasional.

Diana, N. (2012). Manajemen Pendidikan Berbasis Budaya Lokal Lampung (Analisis Eksploratif Mencari Basis Filosofis). Analisis: Jurnal Studi Keislaman, 12(1), 183208. Retrieved from https://media.neliti.com/media/publications/56934-ID-none.pdf

Daryanto. (2012). Perubahan Pendidikan dalam Masyarakat Sosial Budaya. Bandung: PT. Sarana Tutorial Nurani Sejahtera.

Elfira, M. (2013). Model Kepemimpinan Berbasis Kearifan Lokal di Minangkabau dan Bugis. Makalah. Tidak diterbitkan. 
Fathiyah, F., Cangara, H., \& Rahman, N. (2018). Pappaseng: Pewarisan Pesan Pesan Komunikasi Budaya Dalam Pembentukan Karakter Perempuan Bugis Di Sulawesi Selatan. KAREBA: Jurnal Ilmu Komunikasi, 6(1), 120128. Retrieved from http://journal.unhas.ac.id/index.php/ kareba/article/viewFile/5171/2791

Giddens, A. (1990). The Consequences Of Modernity. Cambridge: Polity Press.

Handayani, T. (2008). Pengembangan Sumber Daya Manusia di antara Peluang \& Tantangan. Jakarta: LIPI Pusat Penelitian Kependudukan.

Iswary, E. (2012). Orientasi Pendidikan Karakter Berbasis Kearifan Lokal Makassar: Penguatan Peran Bahasa Ibu Menuju Good Society, dalam Suardiana, I Wayan \& Astawan, Nyoman. Kearifan Lokal dan Pendidik-an Karakter Prosiding Konferensi Internasional Budaya Daerah ke-2 (KIBD II). Bali: Denpasar, 22-23 Februari.

Iskandar. (2016). Bentuk, Makna, Dan Fungsi Pappaseng Dalam Kehidupan Masyarakat Bugis Di Kabupaten Bombana. Jurnal Bastra (Bahasa dan Sastra), 1(2).

Jahid, J. (2011). Mengungkap Lembaran Kearifan Lokal Kota Labuan Bajo. Cetakan 1. Makassar: Alauddin University Press.

Jemmain, N. F. N. (2011). Aktualisasi Nilai Pappaseng Dalam Rangka Pembangunan Karakter Bangsa. Jurnal Sawerigading, 17(3), 357-364. Retrieved from http://sawerigading.kemdikbud.go.id/index.php/sawerigading/article/ view/387/203

Jumrana. (2018). Pappaseng Sebagai Karakter Masyarakat Bugis Sulawesi Selatan. DOI: 10.31227/osf. io/4trcm. Retrievd from https://osf.io/preprints/inarxiv/4trcm/

Koentjaraningrat. (2015). Pengantar Ilmu Antropologi. Jakarta: Rineka Cipta.

Kurniawan, H. (2018). Nilai-Nilai Kearifan Lokal Tradisi Betabuh Dalam Perspektif Moralitas Islam (Analisis Deskriptif Masyarakat Kecamatan Way Khilau Kabupaten Pesawaran). Tesis. Universitas Islam Negeri (UIN) Raden Intan Lampung. Retrieved from http://repository.radenintan.ac.id/5803/1/TESIS\%20HERI\%20KURNIAWAN.pdf

Liliweri, A. (2005). Prasangka dan Konflik Komunikasi Lintas Budaya Masyarakat Multikultur. Yogyakarta: LKiS Pelangi Aksara.

Mubah, A., S. (2011). Strategi Meningkatkan Daya Tahan Budaya Lokal dalam Menghadapi Arus Globalisasi. Jurnal Unair, 24(4), 302-308. Retrieved from http://www.
journal.unair.ac.id/filerPDF/03\%20Safril\%20Strategi\%20 Meningkatkan\%20Daya\%20Tahan \%20Budaya\%20 Lokal\%20Safril\%20mda.pdf

Masita. (2012). Pendidikan Karakter Berbasis Budaya Lokal Pada Masyarakat Muslim. Jurnal Studi Kemasyarakatan Islam, 15(2). Retrieved from http://ejournal.umm. ac.id/index.php/salam/article/view/1668

Ma'mur, J. (2012). Buku Panduan Internalisasi Pendidikan Di Sekolah. yogyakarta :Diva press.

Mallombasi, H., M., Syuaib, dkk. (2012). Pappaseng: Wujud Idea Budaya Sulawesi Selatan. Makassar: Bidang Sejarah dan Kepurbakalaan, Dinas Kebudayaan dan Kepariwisataan Provinsi Sulawesi Selatan.

Mustafa. (2013). Nilai Kejujuran Dalam Pappaseng Tomatoa ("Honesty Value In "Pappaseng Tomatoa"). Jurnal Sawerigading, 19(2), pp 197-205.

Mansyur, U. (2016). Pemanfaatan Nilai Kejujuran Dalam Cerpen Sebagai Bahan Ajar Berbasis Pendidikan Karakter. In Mengais Karakter dalam Sastra: HISKI Makassar. https://doi.org/10.17605/OSF.IO/Z4T 3Y. Retrieved from https://osf.io/preprints/inarxiv/s8xag/

Mutmainnah, S. A. (2018). Pappaseng To Matoa Dalam Masyarakat Bugis: Karakter Pendukung Bagi Manusia. DOI: $10.31227 /$ osf.io/cwuxg

Noor, R., M. (2011). Pendidikan Karakter Berbasis Sastra Solusi Pendidikan Moral Yang Efektif. Yogyakarta: Ar Ruzz Media.

Nuraini, I., \& Agus, A., A. (2016). Penerapan Pendidikan Karakter Berbasis Budaya Lokal (Studi Kasus pada SMA Negeri 1 Wera Kab. Bima). Jurnal Tomalebbi, (2), 43-52.

Nurhaeda, N. (2018). Revitalisasi Nilai-Nilai 'Pappaseng'sebagai Kearifan Lokal Masyarakat Bugis: Konseling Eksistensial. In Prosiding Seminar Nasional Bimbingan dan Konseling (Vol. 2, No. 1, pp. 295-313). Retrieved from http://prosiding.unipma.ac.id/index.php/ SNBK/article/view/503

Punagi, A. Abu Bakar, Dkk. (1983). Pappaseng (Wasiat Orang Tua Dulu). Ujung Pandang: YKSS.

Pelras, C. (2006). Manusia Bugis. Jakarta: Nalar bekerjasama dengan Forum Jakarta-Paris, Ecole Francaise dee Extreme-Orient (EFEO).

Priyatna, A. (2011). Parenting For Character Building Panduan Bagi Orang Tua Untuk Membangun Karakter Anak Sejak Dini. Jakarta: PT Alex Media Komputindo Kelompok Gramedia. 
Rosidi, A. (2010). Mencari Sosok Manusia Sunda. Jakarta: Pustaka Jaya.

Rahmi, S. (2016). Karakteristik Pridadi Ideal Konselor Dalam Perspektif Budaya Bugis. Jurnal Konseling Indonesia, 2(1), pp 124-132.

Rukiyati. (2017). Pendidikan Moral Di Sekolah. Jurnal Humanika, 17(1), 1-11. Retrieved from https://journal.uny. ac.id/index.php/humanika/article/viewFile/23119/11628

Rahmi, S., Mppiare-AT, A. \& Muslihati. (2017). Karakter Ideal Konselor Dalam Budaya Bugis Kajian Hermeneutik Terhadap Teks Pappaseng .Jurnal Pendidikan: Teori, Penelitian dan Pengembangan, 2(2). 228-237. Retrieved from http://journal.um.ac.id/index.php/jptpp/article/ view/8535/4129

Rasak, A., Nasrum., \& Syukur, H. (2019). The Values Of Ancestor's Messages (Pappaseng) In Buginese Tradition (Case Study On Bone Regency Students In UIN Alauddin Makassar). Elite Journal. 6(1). Retrieved from http://journal.uin-alauddin.ac.id/index.php/elite/article/ view/9912/7090

Sanjaya, W. (2007). Kurikulum dan Pembelajaran. Jakarta: Kencana Prenada Media Group.

Setyono, F.X. Gus. (2008). "Pentingnya Pendidikan yang Berakar pada Budaya" dalam Basis No. 07-08.Tahun Ke57, Juli-Agustus. Yogyakarta: Yayasan BP Basis.

Sewang, A., \& Asdy, A. (2010). Etika dalam Kehidupan Orang Mandar. Polman: Yayasan Maha Putra.

Sulhan, N. (2011). Panduan Praktis Pengembangan Karakter Dan Budaya Bangsa Sinergi Sekolah Dengan Rumah. Surabaya: JP Press Media Utama (Jawa Pos Grup).

Suneki, S. (2012). Dampak Globalisasi Terhadap Eksistensi Budaya Daerah. CIVIS, 2(1). Retrieved from http://journal.upgris.ac.id/index.php/civis/article/viewFile/603/553

Setiadi, E., M. (2012). Ilmu sosial budaya dasar. Jakarta: Kencana.

Semi, A., M. (2013). Kritik Sastra. Bandung: Angkasa.

Said, Z. (2014). Aksiologi Politik Hukum: Bugis Makassar dalam Perda. Retrieved from http://repository.stainparepare.ac.id/213/1/UKINA_Repo.pdf

Sutjipto. (2013). "Kurikulum Pendidikan Budaya Pada Satuan Pendidikan Rintisan Cultural Education Curriculum In Pilot Education Units". Jurnal Pendidikan dan Kebudayaan. Vol 19. Hal 472-486.
Suryandari, N. (2017). Eksistensi Identitas Kultural Di Tengah Masyarakat Multikultur Dan Desakan Budaya Global. Jurnal Komunikasi, 11(1), 21-28. Retrieved from https:// media.neliti.com/media/publications/106525-ID-eksistensi-identitas-kultural-di-tengah.pdf

Sugiyono. (2017). Metode Penelitian Kuantitatif, Kualitatif dan R\&D. Bandung: Alfabeta.

Setyaningrum, N., D., B. (2018). Budaya Lokal di Era Global. Ekspresi Seni: Jurnal Ilmu Pengetahuan dan Karya Seni, 20(2), 102-112. Retrieved from http://journal.isi-padangpanjang.ac.id/index.php/Ekspresi/article/ view/392/290

Suparno, S., Alfikar, G., Santi, D., \& Yosi, V. (2018). Mempertahankan Eksistensi Budaya Lokal Nusantara Ditengah Arus Globalisasi Melalui Pelestarian Tradisi Gawai Dayak Sintang. JURNAL PEKAN: Jurnal Pendidikan Kewarganegaraan, 3(1), 43-56. Retrieved from http://jurnal.stkippersada.ac.id/jurnal/index.php/PEKAN/article/ view/144/140

Suhra, S. (2018). Nilai-Nilai Pendidikan Karakter Dalam Budaya Masyarakat Bugis Bone. Jurnal Darussalam; Jurnal Pendidikan, Komunikasi dan Pemikiran Hukum Islam Vol. XI, No 1, pp 222-241. Retrieved from https://ejournal. iaida.ac.id/index.php/darussalam/article/view/459/337

Tamsil, A. (2019). Representasi Nilai-Nilai Pappasang Di Tanah Mandar (Studi Hermeneutika Fenomenologi) (Doctoral dissertation, Pascasarjana). Retrieved from http:// eprints.unm.ac.id/12706/1/Jurnal.pdf

Wiyono, T. (2010). Rekonstruksi Pendidikan Indonesia. Yogyakarta: Pustaka Pelajar.

Widodo, S., T. (2016). "Peran Kerarifan Lokal dalam Dinamika Universitas". Makalah Seminar Nasioal Lokal Wisdom Towards Universities Competitiveness in Global Perspectives. Surakarta, 5 November.

Widodo, S. T., Suwandi, S., \& Shaddhono, K. (2017). Membangun Moralitas Generasi Muda Dengan Pendidikan Kearifan Budaya Madura Dalam Parebasan. In Proceedings Education and Language International Conference (Vol. 1, No. 1).

Yulinis. (2019). Eksistensi Payung Dalam Kebudayaan Minangkabau Di Era Globalisasi. MUDRA Jurnal Seni Budaya 34(2), pp 275 - 283. Retrieved from https://jurnal. isi-dps.ac.id/index.php/mudra/article/view/711/379

Zamzami, L., \& Hendrawati. (2014). Kearifan Budaya Lokal Masyarakat Maritim Untuk Upaya Mitigasi Bencana Di Sumatera Barat. Jurnal Antropologi: Isu-Isu Sosial Budaya, 16(1), 37-48. Retrieved from http://jurnalantro- 
pologi.fisip.unand.ac.id/index.php/jantro/article/viewFile/18/14 